\title{
Multipotency of skeletal muscle stem cells on their native substrate and the expression of Connexin 43 during adoption of adipogenic and osteogenic fate
}

Article

Accepted Version

Creative Commons: Attribution-Noncommercial-No Derivative Works 4.0

Elashry, M., Heimann, M., Wenisch, S., Patel, K. and Arnhold, S. (2017) Multipotency of skeletal muscle stem cells on their native substrate and the expression of Connexin 43 during adoption of adipogenic and osteogenic fate. Acta Histochemica, 119 (8). pp. 786-794. ISSN 0065-1281 doi: https://doi.org/10.1016/j.acthis.2017.10.002 Available at https://centaur.reading.ac.uk/73227/

It is advisable to refer to the publisher's version if you intend to cite from the work. See Guidance on citing.

To link to this article DOI: http://dx.doi.org/10.1016/j.acthis.2017.10.002

Publisher: Elsevier

All outputs in CentAUR are protected by Intellectual Property Rights law, including copyright law. Copyright and IPR is retained by the creators or other copyright holders. Terms and conditions for use of this material are defined in the End User Agreement. 


\section{www.reading.ac.uk/centaur}

\section{CentAUR}

Central Archive at the University of Reading

Reading's research outputs online 


\title{
Multipotency of skeletal muscle stem cells on their native substrate and the expression of Connexin 43 during adoption of adipogenic and osteogenic fate
}

\author{
Mohamed I. Elashry a, d, *, Manuela Heimann ${ }^{\mathrm{a}}$, Sabine Wenisch ${ }^{\mathrm{b}}$, Ketan Patel ${ }^{\mathrm{c}}$, Stefan Arnhold ${ }^{\mathrm{a}}$ \\ a Institute of Veterinary Anatomy, Histology and Embryology, Justus Liebig University of Giessen, 35392, Germany \\ b Clinic of Small Animals, c/o Institute of Veterinary Anatomy, Histology and Embryology, Justus Liebig University of Giessen, 35392, Germany \\ c School of Biological Sciences, Hopkins building, Whiteknights, University of Reading, RG6 6UB, United Kingdom \\ d Anatomy and Embryology Department, Faculty of Veterinary Medicine, University of Mansoura, 35516, Egypt
}

\section{A R T I CLE INFO}

\section{Introduction}

Skeletal muscle contains a resident stem cell population called Satellite cells (SC) which have a huge capacity to regenerate damaged tissue. Transplantation of a single fiber consisting of less than ten cells is able to generate tens of thousands of myonuclei within a matter of a few weeks (Collins et al., 2005). SC take their name from their peripheral position relative to the muscle fiber (Mauro, 1961). They are located under the basal lamina, in direct contact with the sarcolemma of muscle fibers. In undamaged muscle, they are relatively metabolically inactive as indicated by their low cytoplasmic content and they exist in a quiescent state. However, they express certain markers including Pax7 that aid their identification (Zammit et al., 2006). Upon muscle damage, SC become activated by inducing a number of genes including $M y o D$ that encodes a member of the Myogenic Determination Factor family (MRF) of transcriptions factors (Zammit et al., 2006). Activation of SC permits cell division as well as migration. Initially, SC migrate under the basal lamina but then take up a supra-basal position by remodeling their overlying extra-cellular matrix (Otto et al., 2011). Activated SC can either revert to their quiescent state by down-regulating MyoD while maintaining Pax7 or can commit to myogenic differentiation by shutting off Pax7 expression and inducing the expression of Myogenin, another member of the MRF family (Zammit et al., 2006).

Following acute muscle injury, SC progeny only form muscle cells (Collins et al., 2005). However, they are multipotent and under appropriate conditions can adopt an adipogenic or osteogenic fates (Katagiri et al., 1994; Yamaguchi et al., 1991). A number of diseases including Duchenne Muscular Dystrophy result in the formation of adipose de- posits in skeletal muscle (Li et al., 2015). The origin of the adipose deposits is much debated and some have postulated that they are derived from SC. Understanding the mechanisms that control SC fate change away from the myogenic lineage is of considerable clinical value since adipose tissue is believed to hinder muscle regeneration (Cordani et al., 2014).

A number of studies highlight the importance of the surface matrix in almost all aspects of cell behavior. The matrix governs the mechanisms by which cells migrate. For example, SC on their native substrate, the muscle fiber, move through an amoeboid-based mechanism, yet when the same cells are placed on plastic they develop lamellipodia (Morash et al., 2017; Otto et al., 2011) Surface matrix governs not only how cells migrate but ultimately can control what they become by regulating their fate. Engler and colleagues have elegantly demonstrated that hydrogel stiffness over two orders of magnitude directs fate decisions of human mesenchymal stem cells, and ultimately determines whether they form bone, muscle or neurons (Engler et al., 2006).

We have previously shown that seeding non-muscle stem cells onto the surface of muscle fibers induces them to adopt a SC mode of migration (Morash et al., 2017). More remarkable, we showed that adipose derived stem cells undergo a myogenic conversion following culture on the myofiber surface (Morash et al., 2017). These and other studies show that the native substrate of SC supports myogenic characteristics.

Here we examined the impact of adipogenic and osteogenic culture conditions on SC located on muscle fibers. Furthermore, we investigated the expression of Connexin 43 on muscle SC and how it was influenced by adipogenic and osteogenic culture conditions. Connexin 43 (Cx43) is a gap junction protein that regulates intercellular transfer of

Abbreviation: SC, satellite cells; Cx43, connexin43; PPAR $\gamma$, peroxisome proliferator-activated receptor gamma; FABP4, fatty acid binding protein 4; OC, osteocalcin; OP, osteopontin; MHC, myosin heavy chain; AP2, adipocytes protein2; ALP, alkaline phosphatase; BMP-2, bone morphogenetic protein-2.

* Corresponding author at: Institute of Veterinary Anatomy, Histology and Embryology, Justus Liebig University of Gießen, Frankfurter Str. 98 , 35392 Giessen, Germany.

Email address: mohammed.elashry@vetmed.uni-giessen.de (M. Heimann) 
signals and molecules less than $1 \mathrm{kD}$ (Kumar and Gilula, 1996). Cx43 plays a pivotal role during development and maintenance of the myocardium via modulation of cell polarity and the migration potential of cardiomyocytes (Rhee et al., 2009). Furthermore, Cx43 is expressed during muscle regeneration following cardiotoxin and $\mathrm{BaCl}_{2}$ injection implying a role in this process (Araya et al., 2005).

\section{Materials and methods}

\subsection{Animals}

All experimental procedures were approved by the institutional ethics committee and the Regierungspräsidium Gießen GI 20/10 Nr. 105/2014. 6-8 week old C57/Black 6 male mice were kept in conventional housing at the animal facility of Justus Liebig University of Giessen. Mice were provided water and chow diet ad libitum.

\subsection{Muscle dissection}

Hind limb M. tibialis anterior (TA) and M. soleus (SOL) were dissected and snap frozen in Tissue-Tec OCT (Sakura, Germany) using isopentane precooled with liquid nitrogen. $10 \mu \mathrm{m}$ mid-belly cryostat sections were placed on poly-L-lysine coated slides (VWR Germany) and stored in $-80{ }^{\circ} \mathrm{C}$ for immunohistochemistry.

\subsection{Isolation of SC/Myoblasts with or without the myofibers}

M. extensor digitorum longus (EDL) was used due to its amenability to produce single muscle fibers (Keire et al., 2013; Pasut et al., 2013). EDL muscles were dissected and extra-cellular matrix partially digested using $0.2 \%$ collagenase IV (Biochrome, Germany) in DMEM (Gibco, Life technologies, Germany) at $37{ }^{\circ} \mathrm{C}$ with $5 \% \mathrm{CO}_{2}$ for $1.5-2 \mathrm{~h}$. Hind limb muscles were dissected into ice-cold PBS containing 1\% penicillin/streptomycin (Gibco Fisher Scientific) for myoblasts extraction. All tendons, nerves and blood vessels were removed under sterile conditions. Muscles were minced, centrifuged at $2000 \mathrm{~g}$ for $5 \mathrm{~min}$ and digested in $0.1 \%$ collagenase IV in DMEM with shaking at $37^{\circ} \mathrm{C}$ for $40 \mathrm{~min}$. Digested samples were triturated using an 18 gauge needle. Equal volume of $2 \%$ FCS (fetal calf serum, Biocell) DMEM was added and the mixture filtered through a $70 \mu \mathrm{m}$ cell strain before centrifuging at $2000 \mathrm{~g}$ for $10 \mathrm{~min}$. Cell pellets were resuspended in fresh media and cells counted using a hemocytometer. Surface markers CD44 and CD90 as well as preplating for $48 \mathrm{~h}$ was used for SC selection as previously described (Chirieleison et al., 2012; Scimeca et al., 2015). Briefly, $10 \mu$ l of goat anti mouse IgG magnetic bead solution was incubated with 5-10 $\mu$ g of anti-mouse CD90 and CD44 (1:50, DSHB) primary antibodies in 5\% FCS/PBS with agitation at $4 \mathrm{C}^{\circ}$ for $1 \mathrm{~h}$. After washing three times in PBS, $1 \times 10^{7}$ cells were incubated with bead-coated primary antibodies at $4{ }^{\circ} \mathrm{C}$ for $30 \mathrm{~min}$. Bead coated cells were magnetically separated and washed in PBS. To reduce non-satellite cells contamination, harvested cells were preplated in $20 \%$ FCS/Hamís F-10 (Gibco Fisher Scientific) supplemented with 1\% penicillin and streptomycin for $48 \mathrm{~h}$. Non-attached cells were centrifuged at $800 \mathrm{~g}$ for $5 \mathrm{~min}$, the pellet suspended in 10\% FCS/DMEM and seeded on collagen coated flasks $(0.4 \%$ bovine calf skin/acetic acid, Biochrom, Germany) until 50-70\% confluency. The expression of surface marker CD44, CD90 and specific myoblasts marker MyoD were assessed using the immunofluorescent staining (Fig. 2g-I and supplementary Fig. $1 \mathrm{~d}$, e and f). The cells at passage $1-3$ showing greater than $80 \%$ positivity for MyoD were used in all experiments.

\subsection{SC culture and differentiation induction}

SC with intact fibers (15-20 fibers) were cultivated in triplicate in 24 well plates. Alternatively $1 \times 10^{4}$ cells/well were grown in 24 well plates in 10\% FCS/DMEM as a monolayer. After $48 \mathrm{~h}$, the basal medium was removed and replaced by one of the following: Proliferation medium (PM), $1 \mathrm{mg} / \mathrm{ml}$ glucose DMEM containing 5\% FCS. Myogenic differentiation medium (MD) $1 \mathrm{mg} / \mathrm{ml}$ glucose DMEM supplemented with 5\% horse serum (Millipore, Darmstadt, Germany), $2.5 \mathrm{ng} /$ $\mathrm{ml}$ human Fibroblast Growth Factor (Invitrogen), 1\% Sodium pyruvate (Sigma). Adipogenic differentiation medium (AD) $4.5 \mathrm{mg} / \mathrm{ml}$ glucose DMEM supplemented with 5\% FCS, $1 \mu \mathrm{M}$ dexamethasone (Sigma), $5 \mu \mathrm{g} / \mathrm{ml}$ Insulin-transferrin-selenium and $5 \mu \mathrm{M}$ Rosiglitazone (Sigma). Osteogenic differentiation medium (OD) $1 \mathrm{mg} / \mathrm{ml}$ glucose DMEM supplemented with 5\% FCS, $0.1 \mu \mathrm{M}$ dexamethasone, $2.5 \mu \mathrm{M}$ retinoic acid (Sigma), $250 \mu \mathrm{M}$ ascorbic acid (Sigma), $100 \mathrm{ng} / \mathrm{ml}$ BMP-2 (Peprotech, Germany and $10 \mathrm{mM} \beta$-glycerophosphate (Fluka, Germany). Myofibers were cultured for up to $120 \mathrm{~h}$ whereas myoblasts were maintained for up to 3 weeks.

\subsection{Immunohistochemical staining}

The cells and muscle sections were fixed in 4\% paraformaldehyde (PFA) for $10 \mathrm{~min}$, washed twice with PBS for $10 \mathrm{~min}$, permeabilized with buffer containing $20 \mathrm{mM}$ Hepes, $300 \mathrm{mM}$ sucrose, $50 \mathrm{mM} \mathrm{NaCl}$, $3 \mathrm{mM} \mathrm{MgCl}_{2}$ and $0.5 \%$ Triton-X100 (pH 7) for $15 \mathrm{~min}$, blocked in 5\% FCS with $0.05 \%$ Triton X-100 in PBS for $30 \mathrm{~min}$. They were then incubated with primary antibodies overnight at $4{ }^{\circ} \mathrm{C}$. All the primary antibodies were purchased from DSHB, USA unless otherwise stated. The following primary antibodies were used; anti-mouse CD90 1:20, CD44 1:20, Pax7 1:30, MyoD 1:100 (B\&D Pharmingen), myogenin 1:30, adipocytes protein 2 1:30 (AP2), alkaline phosphatase 1:30 (ALP) and Cx43 1:100 (Invitrogen). Expression of myosin heavy chain (MHC) type I, IIA and IIB and total muscle fibers was determined using anti mouse A.4840 1:50, A.474 1:50, BFF3 1:50 and Lam BS 1:30 respectively. Incubation with secondary antibodies: goat anti-mouse fluorescent isothiocyanate (FITC) and anti-mouse IgG Cy3 was carried out in the dark at room temperature for $1 \mathrm{~h}$. Immunohistochemical staining for $\mathrm{Cx} 43$ was performed using anti-mouse horseradish peroxidase (HRP 1:500, Dianova, Germany) for $30 \mathrm{~min}$ at $37^{\circ} \mathrm{C}$. HRP was developed by dissolving $4 \mathrm{mg} / \mathrm{ml}$ dimethylformamide (AEC) 3-Amino-9-ethylcarbazole and $2.5 \mu \mathrm{H} \mathrm{H}_{2} \mathrm{O}_{2}$ in $50 \mathrm{mM}$ sodium acetate ( $\mathrm{pH}$ 5.2) for $30 \mathrm{~min}$. Incubation omitting primary antibodies served as a negative control (Supplementary Fig. 1). The slides were mounted using aqua Polymount (Polysciences, Germany). Nuclei were visualized using DAPI (ThermoFisher) or a hematoxylin (Sigma). Quantification of SC was performed by counting the number of Pax7, MyoD, myogenin and Cx43 positive cells per myofiber (minimum of 15-20 fibers were quantified for every trial). MyoD positive myoblasts were counted in 10 random fields per well in 24 well plate at $48 \mathrm{~h}$ post induction. Evidence of myogenic differentiation was determined using phalloidin actin filaments staining 1:50 (Sigma) for $30 \mathrm{~min}$. For examination of adult muscle phenotypes and Cx43 distribution, the whole muscle was photographed $(\mathrm{N}=3$ for each muscle) using the Axio-imager fluorescent microscope linked to Axiovision software (Zeiss, Germany). Individual images were merged using Photoshop (CS6 extended) software. Manual counting was carried out for the determination of total fiber number, percentage of MHCI, IIA, and IIB and Cx43 positive signals. The percentage of MHCIIX was determined by subtracting all the MHC types from the total myofiber number. 


\subsection{MTT proliferation assay}

Muscle myoblasts were grown in triplicates under basal, myogenic, adipogenic and osteogenic differentiation conditions for up to 2 weeks. MTT assay was performed as previously reported (Janeczek et al., 2013 and Yu et al., 2013). Briefly, the media was removed and the cells were incubated with 1:10 DMEM diluted MTT reagent (thiazolyl blue tetrazolium $0.5 \%$ in PBS) at $37{ }^{\circ} \mathrm{C}$ for $4 \mathrm{~h}$. MTT reagent was then replaced by $200 \mu \mathrm{l}$ DMSO and incubated at $37{ }^{\circ} \mathrm{C}$ for $10 \mathrm{~min}$. The cells were transferred to a 96 well microplate and the optical densities (OD) was measured at $570 \mathrm{~nm}$ using microplate reader (Tecan) loaded with Magellan 6 software.

\subsection{Real time-quantitative polymerase chain reaction (RT-qPCR)}

RNA extraction was performed using a spin column RNA mini kit (Analytik Jena, Germany), quantified (using a Biophotometer, Eppendorf) and treated with DNase1 (Roche, Germany). Reverse transcription was carried out using master mix and reverse transcriptase (Thermofisher). QRT-PCR was performed in triplicate using SYBER green qPCR-master mix (Promega) with $10 \mathrm{pM}$ primers (see Table 1) for 35 cycles of $5 \mathrm{~min}$ at $95{ }^{\circ} \mathrm{C}, 30 \mathrm{~s}$ at $94^{\circ} \mathrm{C}, 30 \mathrm{~s}$ at $60{ }^{\circ} \mathrm{C}, 30 \mathrm{~s}$ at $72{ }^{\circ} \mathrm{C}$. PCR master mix without cDNA served as a negative control. Gene expression was normalized to gene $18 \mathrm{~S}$ expression using $\Delta \mathrm{Ct}$ method (Schmittgen and Livak, 2008).

\subsection{Oil red $O$ staining}

Adipogenesis was assessed by fixing cells in 4\% PFA for $10 \mathrm{~min}$, washing in PBS for 5 min followed by two 3 min washes in water. The cells were incubated with Oil red O for $30 \mathrm{~min}$. Cells were washed in distilled water and mounted with Kaiser's gelatin (Roth, Karlsruhe, Germany). Non-induced cells were used as a negative control (supplementary Fig. 1h).

\subsection{Alizarin red staining}

Osteogenesis was examined by fixing cells in 4\% PFA for $10 \mathrm{~min}$, washing three times in PBS followed by distilled water for $10 \mathrm{~min} .1 \%$

Table 1

Primers sequences used for RT-qPCR.

\begin{tabular}{|c|c|c|}
\hline $\begin{array}{l}\text { Gene } \\
\text { Name }\end{array}$ & Primer sequence & $\begin{array}{l}\text { Product size } \\
\text { (bp) }\end{array}$ \\
\hline MyoD & $\begin{array}{l}\text { Forward: GTGAATGAGGCCTTCGAGAC } \\
\text { Reverse: GAGCCTGCAGACCTTCGATG }\end{array}$ & 115 \\
\hline Myogenin & $\begin{array}{l}\text { Forward: GAAGAAAAGGGACTGGGGAC } \\
\text { Reverse: TCTTGAGCCTGCGCTTCTCC }\end{array}$ & 136 \\
\hline FABP4 & $\begin{array}{l}\text { Forward: CATCAGCGTAAATGGGGATTTG } \\
\text { Reverse: CTTCCTGTCGTCTGCGGTGA }\end{array}$ & 115 \\
\hline$P P A R \gamma$ & $\begin{array}{l}\text { Forward: CACTATGGAGTTCATGCTTGTG } \\
\text { Reverse: } \\
\text { CGACAGTACTGACATTTATTTCTAC }\end{array}$ & 133 \\
\hline Osteocalcin & $\begin{array}{l}\text { Forward: CAAGCAGGAGGGCAATAAGG } \\
\text { Reverse: TACTGGTTTGATAGCTCGTCAC }\end{array}$ & 135 \\
\hline Osteopontin & $\begin{array}{l}\text { Forward: } \\
\text { GAATCTGACGAATCTCACCATTC } \\
\text { Reverse: CAGTCCGTAAGCCAAGCTATC }\end{array}$ & 134 \\
\hline $18 S$ & $\begin{array}{l}\text { Forward: GGCGTCCCCCAACTTCTTA } \\
\text { Reverse: GGGCATCACAGACCTGTTATTG }\end{array}$ & 76 \\
\hline
\end{tabular}

$(\mathrm{w} / \mathrm{v})$ Alizarin red $\mathrm{pH} 4.2$ was added for $15 \mathrm{~min}$. Cells were washed with distilled water and mounted with Kaiser's gelatin. Non-induced cells were used as a negative control (Supplementary Fig. 1i)

\subsection{Statistical analysis}

Two-way ANOVA was performed to examine the impact of myogenic, adipogenic and osteogenic differentiation medium compared to proliferation medium after $48 \mathrm{~h}$, day 7 and day 14 on the myoblasts viability as well as the expression of myogenic (MyoD and myogenin), adipogenic (PPAR $\gamma$ and FABP4) and osteogenic (Osteocalcin and Osteopontin) gene expression at day 7,14 and 21 (the experiments were run in triplicates). One-way ANOVA was performed to assess SC total number, SC clusters and SC per clusters at 48 and $72 \mathrm{~h}$ per myofiber (minimum of 15-20 fibers were quantified in triplicates for each condition), number of the MyoD positive myoblasts at $48 \mathrm{~h}$ (in 10 random fields per well in 24 well plate at $48 \mathrm{~h}$ post induction), Cx43 positive SC up to $120 \mathrm{~h}$, the percentage of MHC type I, IIA, IIX, IIB and Cx43 localization for TA and SOL muscles $(\mathrm{N}=3)$. Multiple comparisons and the interactions were examined using Tukey's Post hoc test. All data are presented as means \pm SEM. $\mathrm{P}<0.05$ adopted to be significant difference.

\section{Results}

3.1. The influence of adipogenic and osteogenic promoting conditions on SC cultured on their native substrate

We first determined the robustness of the myogenic program of SC when they were on their native substrate by challenging them with conditions that promote their differentiation into non-muscle lineages. The number of myogenic cells on each fiber was significantly increased by $48 \mathrm{~h}$ and $72 \mathrm{~h}$ after exposure to myogenic medium $(\mathrm{P}<0.01$ and 0.0001 respectively) compared to control proliferation medium (Fig. 1a-e). However, exposure of fibers to adipogenic medium resulted in a significant decrease in the number of myogenic cells at both times ( $\mathrm{P}<0.01$ and 0.05 respectively) compared to control medium (Fig. 1d and e). In contrast, osteogenic medium failed to influence the number of myogenic cells by $48 \mathrm{~h}$ (Fig. 1d). However, it did inhibit the development of myogenic cells by $72 \mathrm{~h}(\mathrm{P}<0.05)$ compared to control (Fig. 1e). SC, once activated, migrate and form clusters which can be used as an indication of their migratory ability. We examined the formation of satellite cell clusters on fibers exposed to different fate-inducing medium. The formation of clusters was promoted by myogenic medium at both $48 \mathrm{~h}$ and $72 \mathrm{~h}(\mathrm{P}<0.001$ and 0.01 respectively) compared to control (Fig. 1f-g). In contrast, adipogenic medium inhibited the formation of clusters at $48 \mathrm{~h}(\mathrm{P}<0.001)$ compared to control (Fig. $1 \mathrm{f})$. Osteogenic medium had no effect in terms of cluster formation compared to control conditions at $48 \mathrm{~h}$ or $72 \mathrm{~h}$ (Fig. 1f-g). Lastly, we investigated the composition of each cluster and determined the number of myogenic cells in each cluster at the two time points. We found that myogenic medium induced significantly more myogenic cells in each cluster at both $48 \mathrm{~h}$ and $72 \mathrm{~h}(\mathrm{P}<0.0001$ and $\mathrm{P}<0.05$ respectively) compared to control medium (Fig. 1h-i). Adipogenic medium had no influence in the number of myogenic cells per cluster at $48 \mathrm{~h}$ compared to control medium (Fig. 1h) but reduced it by $72 \mathrm{~h}$ (Fig. 1i). Osteogenic medium induced a slight increase in the number of muscle cells per cluster at $48 \mathrm{~h}$ (Fig. $1 \mathrm{~h}$ ) but this value was significantly lower by $72 \mathrm{~h}$ $(\mathrm{P}<0.0001)$ compared to control medium (Fig. 1i). These results show that adipogenic and osteogenic medium inhibited the proliferation of SC on their native substrate. 


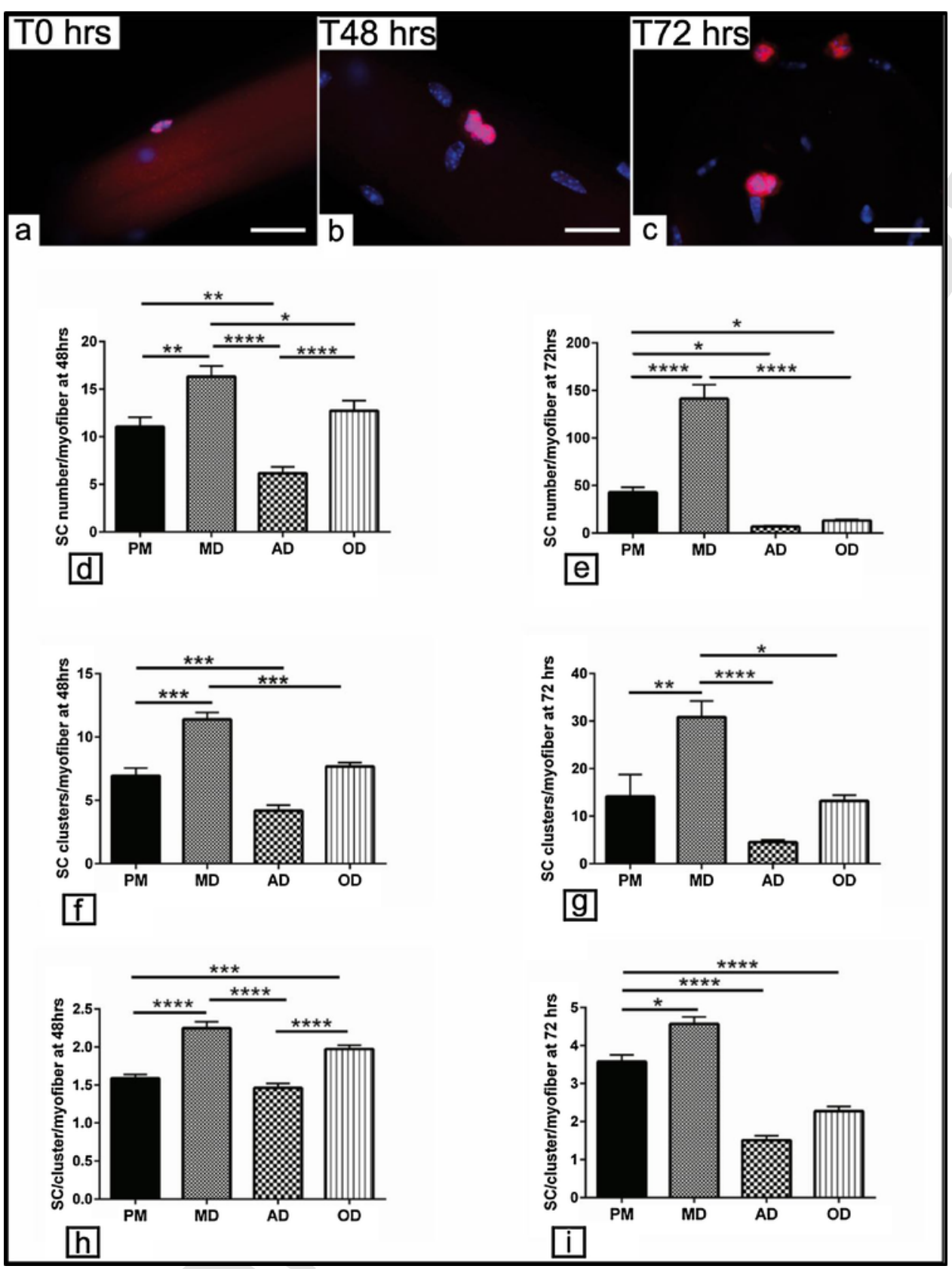

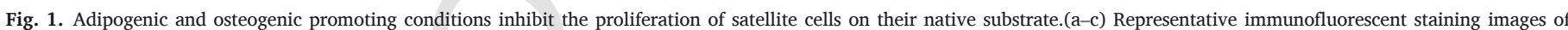

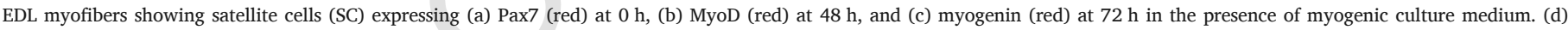

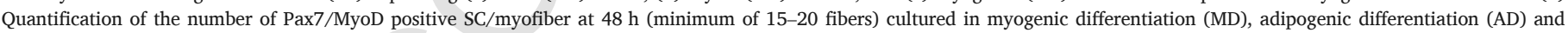

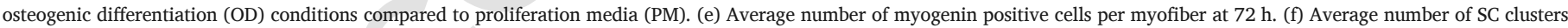

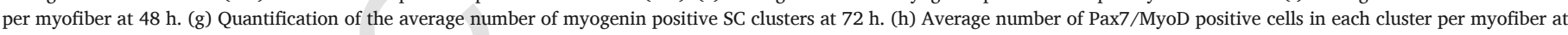

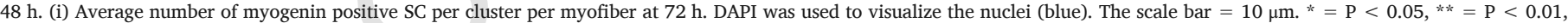
$* * *=\mathrm{P}<0.001$ and $* * * *=\mathrm{P}<0.0001$. All data are presented as means \pm SEM.

\subsection{Adipogenic and osteogenic conditions inhibit primary myoblast} myogenesis by down regulating myogenic regulator factor gene expression and by inducing lineage specific transcripts

Having shown that adipogenic and osteogenic promoting conditions had a profound effect on myofiber positioned SC, we next determined their influence on primary myoblasts cultured as monolayers. Furthermore, we determined their adipogenic and osteogenic potential as well as underlying mechanisms. Myoblasts counting using immunofluores- cence revealed a marked increase in MyoD positive cells after $48 \mathrm{~h}$ under myogenic differentiation conditions compared to control $(\mathrm{P}<0.001)$, adipogenic and osteogenic induction conditions $(\mathrm{P}<0.0001$ ) (Fig. 2a and b). Next, we examined the cellular viability using MTT assay, and found at $48 \mathrm{~h}$ an increase in the cellular proliferation following myogenic induction $(\mathrm{P}<0.05)$ compared to the cells under control or adipogenic medium. After 1 week, the myogenic and adipogenic induced cells showed even greater reductions in cellular proliferation ( $\mathrm{P}<0.05$ and 0.01 respectively) compared to control. In contrast, osteogenic medium caused only later reduction in proliferation at 2 weeks $(\mathrm{P}<0.05)$ compared to control (Fig. 2c). 


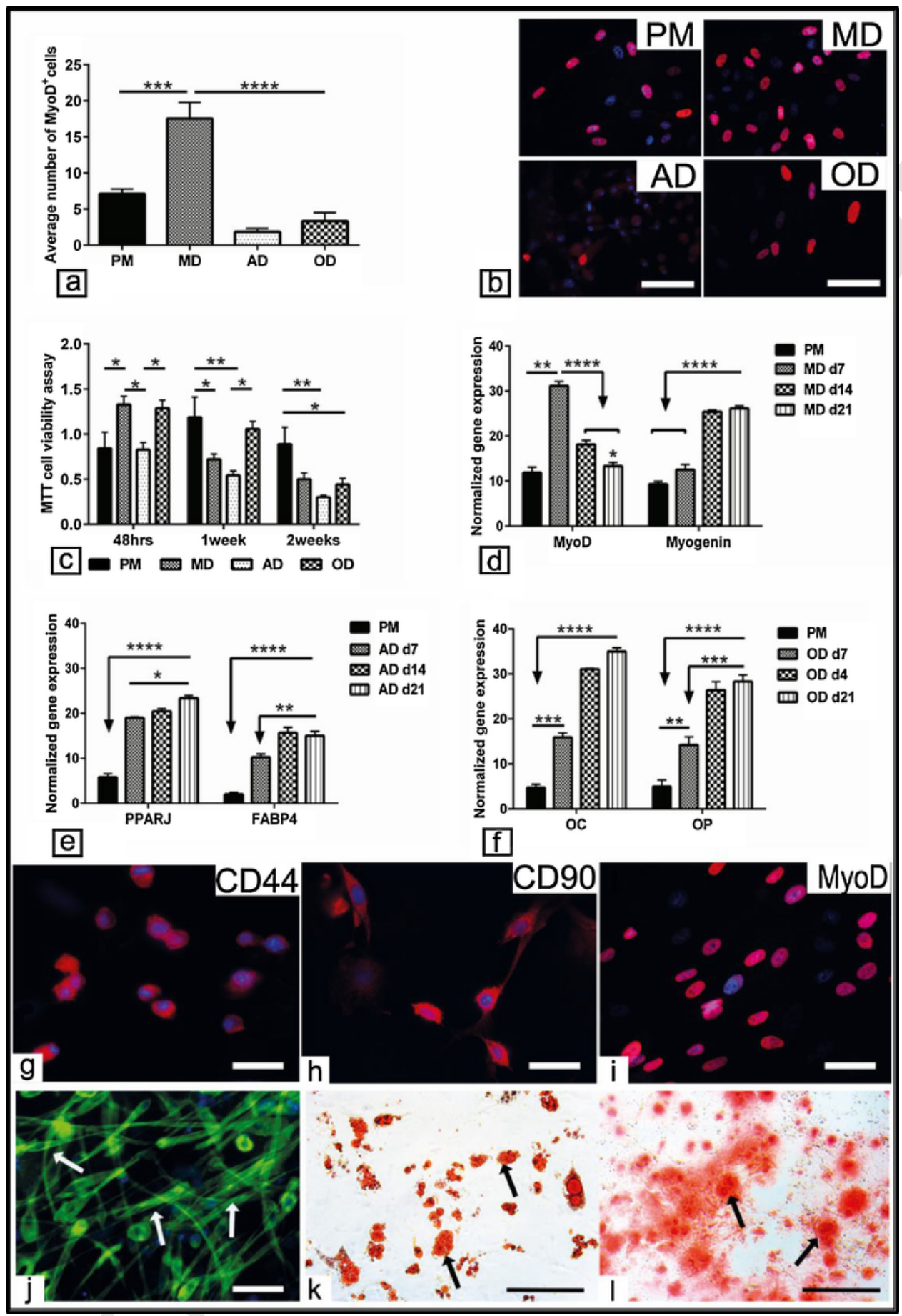

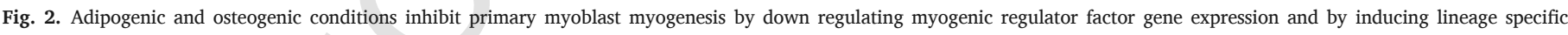

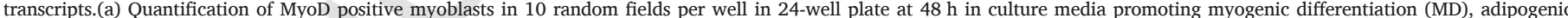

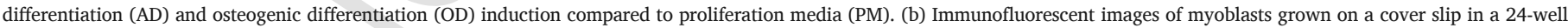

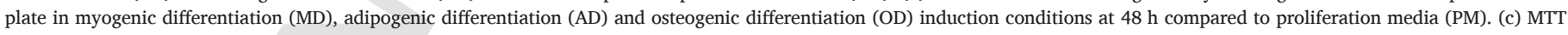

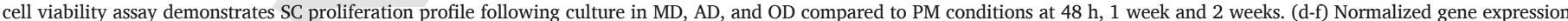

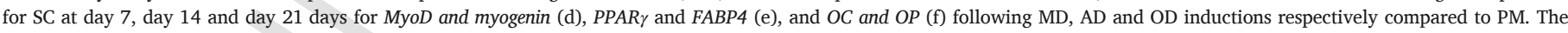

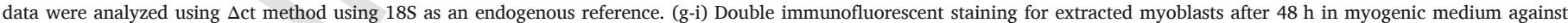

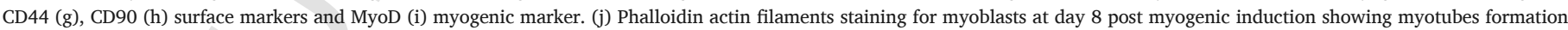

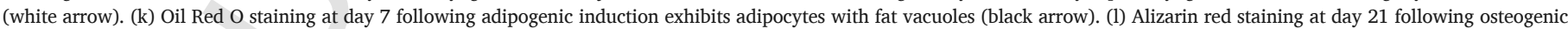

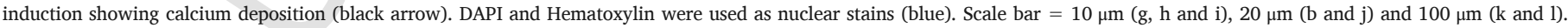
$*=\mathrm{P}<0.05,{ }^{* *}=\mathrm{P}<0.01,{ }^{* *}=\mathrm{P}<0.001$ and $* * * * \mathrm{P}<0.0001$. All data are presented as means \pm SEM.

Next we examined the impact of ectopic culture conditions on genes that promote muscle, adipose and bone development. In conditions that promote muscle differentiation, we found an initial increase in the expression of $M y O D$ which then decreased such that by 21 days it was at the level displayed by cells in proliferation medium (Fig. 2d). The expression of Myogenin was almost the opposite of MyoD in that it 
increased only slightly by 7 days and then amplified in the following two weeks (Fig. 2d). Therefore, myogenic differentiation conditions promoted a biphasic expression of MRF; first a burst of MyoD expression which gradually increased and an initial small increase in Myogenin which ramped up over time. Next, having shown that both adipogenic and osteogenic conditions inhibited the development of myogenic cells, we determined their influence on their fate. We found that the myoblast expression of two key markers of adipogenesis PPAR $\gamma$ (peroxisome proliferator activated receptor gamma) and FABP4 (fatty acid associated binding protein 4) and two key markers of osteogenesis Osteocalcin $(O C)$ and Osteopontin $(O P)$ increased over time when cultured in their respective media (Fig. 2e-f). Having shown that adipogenic and osteogenic media promoted gene expression of tissue associated markers, we determined their impact at the cell level. We first established the myogenic fate of primary muscle cells. Evidence for myogenic commitment was evaluated at day 8 using phalloidin staining for the detection of actin filaments in order to evaluate myotube formation. Several myotube-like structures were detected (Fig. 2j and supplementary Fig. 1g). In adipogenic and osteogenic conditions we detected Oil red $\mathrm{O}$ and the Alizarin red staining, respectively. Our results showed lipid vacuole formation at day 8 of adipogenic induction and calcium deposition at day 21 of osteogenic induction (Fig. 2k, 1 and supplementary Fig. 1h, i). In summary, adipogenic and osteogenic conditions inhibited the development of muscle cells and promoted them to adopt adipose and bone fate through the induction of tissue associated genes.

\subsection{The influence of tissue specific culture conditions on the expression of CX43 by SC on their native substrate}

Previous reports have postulated a role of $\mathrm{Cx} 43$ during myogenic differentiation. Here we determine the impact of culture conditions that inhibit myogenesis on the expression of this protein by SC on muscle fibers. First, we found that $\mathrm{Cx} 43$ was not expressed in quiescent SC following fiber isolation. However, $\mathrm{Cx} 43$ expression displayed a polar localization at the junction between SC and the myofiber after a $48 \mathrm{~h}$ cultivation period (Fig. 3a-a" and supplementary Fig. 1j). At 72-96 h, it was more cytoplasmic in localization (Fig. 3b-b"). At 120 h, Cx43 showed nuclear localization (Fig. 3c-c"). Quantification of $\mathrm{Cx} 43$ positive $\mathrm{SC}$ at $48 \mathrm{~h}$ revealed a significant increase in cell number following myogenic induction ( $\mathrm{P}<0.001$ ) compared to control (Fig. 3d). In contrast, $\mathrm{Cx} 43$ expression was markedly reduced following adipogenic induction $(\mathrm{P}<0.001)$ and showed a minor decrease after osteogenic stimulation compared to control (Fig. 3d).

We next characterized Cx43 expression in differing condition media over time. Following induction of myogenic differentiation, quantification of $\mathrm{Cx} 43$ /myogenin positive SC revealed significant increases for up to a $96 \mathrm{~h}$ cultivation period $(\mathrm{P}<0.0001)$ followed by a decrease at $120 \mathrm{~h}$ compared to control (Fig. 3e). In contrast, adipogenic induction never induced an increase in cells of interest and rather caused an early decrease in Cx43/myogenin positive SC at 72 and $120 \mathrm{~h}$ compared to time-matched control (Fig. 3f). Osteogenic induction also never promoted the development of $\mathrm{Cx} 43 /$ myogenin positive cells. Instead, it promoted a late decrease in Cx43/myogenin positive cells at $120 \mathrm{~h}(\mathrm{P}<0.0001)$ compared to time-matched control as well as a remarkable decrease $(\mathrm{P}<0.05)$ compared to osteogenic induced cells at $96 \mathrm{~h}$ (Fig. 3g). We next examined expression of $\mathrm{Cx} 43$ in the clustering process. In myogenic differentiation medium there was an increase in the number of $\mathrm{Cx} 43$ positive clusters during the 72-96 time window $(\mathrm{P}<0.0001)$ compared to control. Thereafter the numbers of $\mathrm{Cx} 43$ clusters were the same as in proliferation medium (Fig. 3h). In contrast, the number of $\mathrm{Cx} 43$ positive clusters was never greater than the number found in proliferation medium under adipogenic (Fig. 3i) or osteogenic conditions (Fig. 3j). We then assessed whether adipogenic and osteogenic induction impaired the cluster size. The number of $\mathrm{Cx} 43$ positive SC in each cluster was assessed which revealed there was an increase in the size of cluster at $72 \mathrm{~h}(\mathrm{P}<0.0001)$ in the presence of myogenic differentiation medium (Fig. 3k). The size then dropped to levels statistically similar to those of fibers in proliferation medium ( $\mathrm{P}<0.0001$, Fig. 3k). In contrast, adipogenic or osteogenic media never induced an increase in cluster size at any interval examined (Fig. $3 \mathrm{k}$ ). Immunofluorescent staining showed the cluster size and the colocalization of $\mathrm{Cx} 43$ and myogenin following myogenic induction (Fig. 31-l"). Next, we examined the SC expression for adipogenic and osteogenic markers. Immunofluorescent staining revealed expression of the AP2 adipogenic marker (Fig. 3m-m" and supplementary Fig. 1k) as well as the expression of ALP (Fig. 3n-n" and supplementary Fig. 11) at $72 \mathrm{~h}$ following adipogenic and osteogenic inductions, respectively.

\subsection{Cx43 localization in the adult muscle}

Our results indicate that $\mathrm{Cx} 43$ plays a critical role during myogenesis. We next examined whether $\mathrm{Cx} 43$ expression was influenced by the identity of muscle and fiber types. Quantification of the Cx43 immune-reactivity revealed that fibers of the SOL had more $\mathrm{Cx} 43$ positive cells than those from the TA muscle (Fig. 4a, b, d, e, f, $g$ and supplementary Fig. 1m, n). Next we correlated $\mathrm{Cx} 43$ distribution with muscle fibers type. Therefore, the total myofiber number (Fig. 4h, i and supplementary Fig. 1o), as well as, the percentages of MHC types for TA and SOL muscles were quantified. The TA muscle contained more MHC type IIB and IIX glycolytic fibers $(\mathrm{P}<0.0001)$ than the SOL muscle (Fig. 4c, $\mathrm{j}, \mathrm{k}$ and supplementary Fig. 1p). On the other hand, SOL muscle contained more type IIA and type I oxidative fibers $(\mathrm{P}<0.0001)$ compared to TA (Fig. 4c, 1, m, n, o and supplementary Fig. 1q and r). These results suggest that slow muscle contains more $\mathrm{Cx} 43$ positive cells.

\section{Discussion}

Investigation of SC will provide mechanistic insights into their ability to promote muscle regeneration as well as their multipotent nature. Although SC have been shown to be multipotent (Asakura et al., 2001), this property has never been investigated when they are on their native substrate. It is well known that the substrate plays a critical role not only in stem cell behavior (e.g. ability to migrate), but also in terms of their fate. The latter was clearly demonstrated in the classic paper by Engler and colleagues who showed that a simple parameter like substrate stiffness determined whether stem cells differentiated into neurons or muscle cells (Engler et al., 2006). Furthermore it has been shown that the gap junction protein $\mathrm{Cx} 43$ plays a pivotal role in muscle regeneration following injuries (Araya et al., 2005). However, the expression of $\mathrm{Cx} 43$ by SC during the fate making process had never been investigated.

We maintained the environment of the SC niche by culturing them on myofibers which avoided contamination by other cell populations. We detected increases in proliferation, cluster formation and differentiation potential following myogenic induction. However, adipogenic or osteogenic supporting conditions resulted in a delay of myogenesis via reduction of SC proliferation, migration and myogenic differentiation. These results highlight the susceptibility of the myogenic program to environmental factors. Furthermore, we showed that under the conditions used here, we not only inhibited myogenesis but promoted the formation of adipose or osteogenic cells. It is possible that once non-muscle cells have been induced they release factors that further inhibit myogenesis. In keeping with this line of thought are studies that describe adipogenesis inhibiting the proliferation and differentiation of muscle stem cells in diabetes (Fujimaki et al., 2015). 


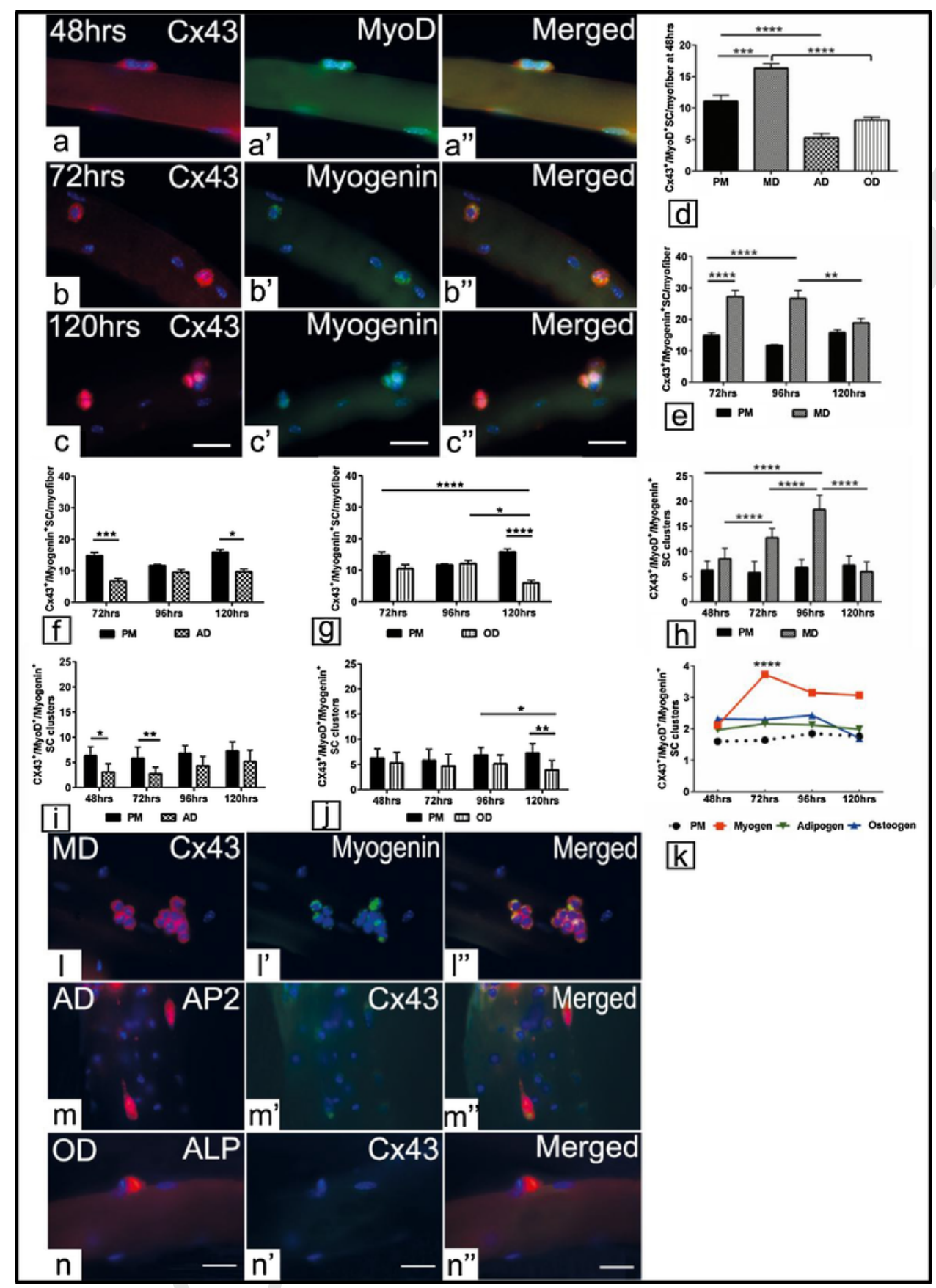

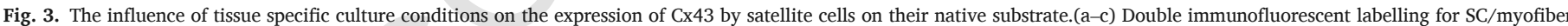

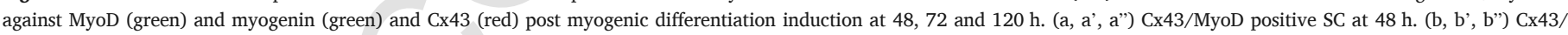

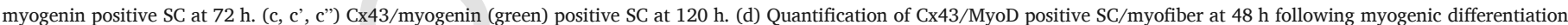

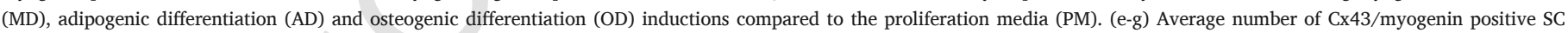

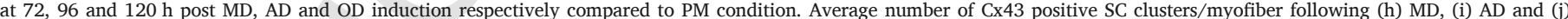

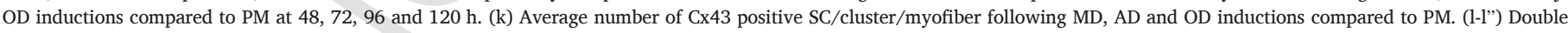

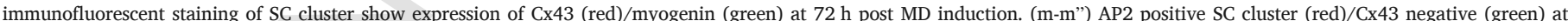

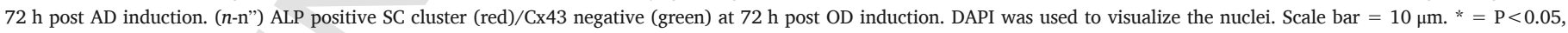
$* *=\mathrm{P}<0.01, * * *=\mathrm{P}<0.001$ and $* * * *=\mathrm{P}<0.0001$. All data are presented as means \pm SEM.

It is well established that failure of proper regeneration leads to replacement of the muscle tissue by fibrous and adipose tissues like in muscular dystrophic diseases (Lin et al., 1969). Our results demonstrate a reduction of myogenic committed cells together with the expression of AP2 and ALP following adipogenic and osteogenic inductions, respectively. We showed that adipogenic and osteogenic condi- tions inhibited the development of $\mathrm{Cx} 43$ expressing muscle cells. These results are in keeping with reports that $\mathrm{Cx} 43$ inhibition with 18 alpha-glycyrrhetinic acid inhibited myogenesis and induced adipogenesis (Yamanouchi et al., 2007), underlining the important role of $\mathrm{Cx} 43$ for myogenesis.

Isolated myoblasts from muscle homogenates showed that myogenic induction causes early $M y o D$ upregulation at day 7 and late Myo- 


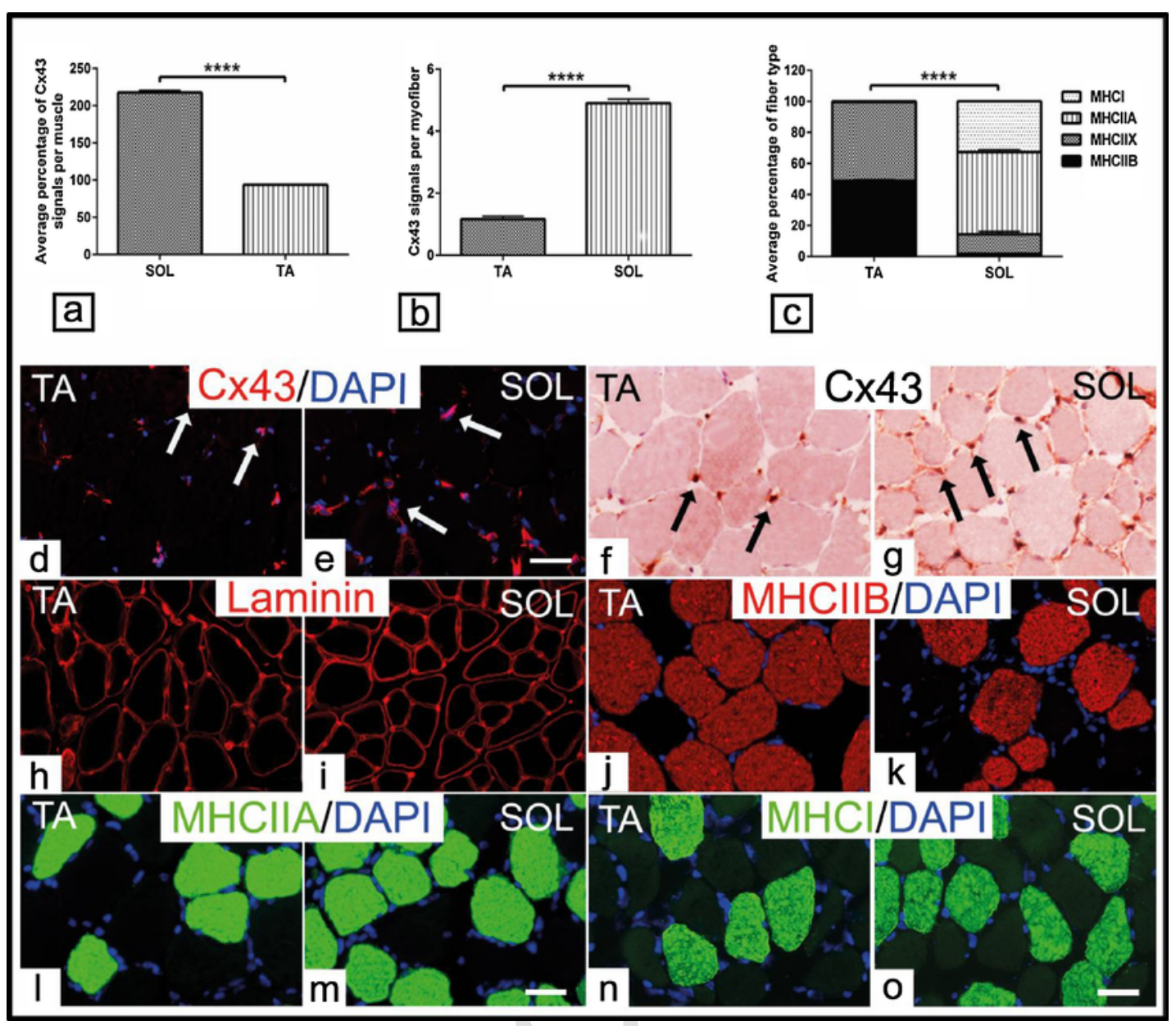

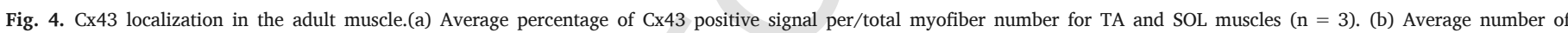

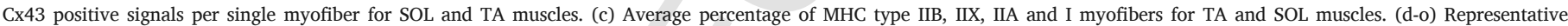

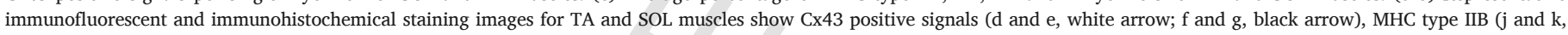

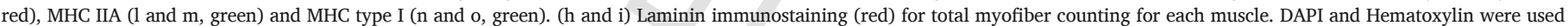
as counterstains. Scale bar $=20 \mu \mathrm{m} .{ }^{* * * *}=\mathrm{P}<0.0001$. All data are presented as means \pm SEM.

genin expression at day 14 and day 21 post induction suggesting a myogenic commitment. Our data are consistent with previous reports showing that following injury, SC proliferation and differentiation is characterized by an upregulation of MyoD, Myf5, myogenin and MRF4 (Fuchtbauer and Westphal, 1992; Grounds et al., 1992). Our results showed an upregulation for PPAR $\gamma$ and FABP4 at day 7, 14, and 21 post adipogenic induction as well as increases in the expression level for $O C$ and $O P$ following osteogenic stimulation. These results clearly show the multipotent nature of SC both on their native substrate and on plastic.

We demonstrated that $\mathrm{Cx} 43$ was expressed in activated but not quiescent SC. During periods of proliferation and early differentiation Cx43 was located at the extremities of cells. Thereafter, $\mathrm{Cx} 43$ was found in the cytoplasm and then in the nucleus. Investigation of $\mathrm{Cx} 43$ expression in oral squamous cell carcinoma revealed that membranous translocation for $\mathrm{Cx} 43$ is required to maintain the gap junction, whereas the cytoplasmic localization is important for its storage (Brockmeyer et al., 2014). Based on these observations, we suggest that Cx43 supports signal and molecule transfer in order to support proliferation and differentiation. Thereafter it may be held in the cytoplasm to support these activities as they are induced.

Our study documented an increase in Cx43/MyoD positive SC/myofiber and $\mathrm{Cx} 43 /$ myogenin following myogenic induction suggesting that $\mathrm{Cx} 43$ as associated in the myogenic commitment as well as termi- nal differentiation. Similar reports revealed that $\mathrm{Cx} 43$ was expressed during myoblasts proliferation and myotube formation (Balogh et al., 1993; Gorbe et al., 2007; Schmalbruch, 1982). These lines of thought are in keeping with studies showing that $\mathrm{Cx} 43$ was upregulated during muscle regeneration following acute injury (Araya et al., 2005; Bakay et al., 2002) and that its deletion perturbs myofiber renewal by decreasing myogenin (Araya et al., 2005).

We show that slow twitch soleus muscle contained a greater number of Cx43 expressing cells than the fast twitch TA muscle. However we have shown that quiescent SC do not express Cx43. Therefore in undamaged muscle, the $\mathrm{Cx} 43$ expression must be in cells other than SC. Cx43 expression is likely to be in endothelial and smooth muscle cells. In agreement with our hypothesis, an independent study revealed $\mathrm{Cx} 43$ expression within endothelial and smooth muscles cells of microvessels (Little et al., 1995; Yeh et al., 1998). Based on the fact that slow twitch muscle contain higher capillary density compared to fast twitch muscle (Gray et al., 1983), it follows that they have more Cx43 expressing cells, which may impact vasomotor reflexes between muscle types.

In summary, we show that SC on their native substrate can be induced to adopt an adipogenic or osteogenic fate following the exposure to specific chemical cues. These regulate not only cell fate but also impact satellite cell progeny proliferation and migration. Furthermore, we show that the expression of $\mathrm{Cx} 43$ is switched on after satellite cell activation. However its expression is labile and can be decreased by cues that promote non-myogenic differentiation. 


\section{Competing interest}

All the authors have declared no conflict of interest regarding the publication of this paper.

\section{Acknowledgement}

We thank Engemann research foundation, Faculty of Veterinary medicine, University of Gießen, BBSRC, United Kingdom (Grant number: BB/H01022X), and Faculty of Veterinary Medicine, University of Mansoura, Egypt for generous funding. Karin Quanz, Center for Excellent Cluster of Cardio Pulmonary System, University of Gießen for graciously providing access to tissue preparation. Eva Maria Kammer, Faculty of Veterinary medicine, University of Gießen for the figures preparation.

\section{References}

Araya, R., Eckardt, D., Maxeiner, S., Kruger, O., Theis, M., Willecke, K, et al, 2005. Expression of connexins during differentiation and regeneration of skeletal muscle: functional relevance of connexin43. J. Cell Sci. 118 (Pt 1), 27-37.

Asakura, A., Komaki, M., Rudnicki, M., 2001. Muscle satellite cells are multipotential stem cells that exhibit myogenic, osteogenic, and adipogenic differentiation. Differ, Res. Biol. Diversity 68 (4-5), 245-253.

Bakay, M., Zhao, P., Chen, J., Hoffman, E.P., 2002. A web-accessible complete transcriptome of normal human and DMD muscle. Neuromuscular Disord. NMD 12 (Suppl 1), S125-41.

Balogh, S., Naus, C.C., Merrifield, P.A., 1993. Expression of gap junctions in cultured rat L6 cells during myogenesis. Dev. Biol. 155 (2), 351-360.

Brockmeyer, P., Jung, K., Perske, C., Schliephake, H., Hemmerlein, B., 2014. Membrane connexin 43 acts as an independent prognostic marker in oral squamous cell carcinoma. Int. J. Oncol. 45 (1), 273-281.

Chirieleison, S.M., Feduska, J.M., Schugar, R.C., Askew, Y., Deasy, B.M., 2012. Human muscle-derived cell populations isolated by differential adhesion rates: phenotype and contribution to skeletal muscle regeneration in Mdx/SCID mice. Tissue Eng. Part A 18 (3-4), 232-241.

Collins, C.A., Olsen, I., Zammit, P.S., Heslop, L., Petrie, A., Partridge, T.A., et al., 2005. Stem cell function, self-renewal, and behavioral heterogeneity of cells from the adult muscle satellite cell niche. Cell 122 (2), 289-301.

Cordani, N., Pisa, V., Pozzi, L., Sciorati, C., Clementi, E., 2014. Nitric oxide controls fat deposition in dystrophic skeletal muscle by regulating fibro-adipogenic precursor differentiation. Stem cells (Dayton, Ohio) 2 (4), 874-885.

Engler, A.J., Sen, S., Sweeney, H.L., Discher, D.E., 2006. Matrix elasticity directs stem cell lineage specification. Cell 126 (4), 677-689.

Fuchtbauer, E.M., Westphal, H., 1992. MyoD and myogenin are coexpressed in regenerating skeletal muscle of the mouse. Dev. Dynamics 193 (1), 34-39.

Fujimaki, S., Wakabayashi, T., Takemasa, T., Asashima, M., Kuwabara, T., 2015. Diabetes and stem cell function. BioMed Res. Int. 2015, 592915.

Gorbe, A., Krenacs, T., Cook, J.E., Becker, D.L., 2007. Myoblast proliferation and syncytial fusion both depend on connexin 43 function in transfected skeletal muscle primary cultures. Exp. Cell Res. 313 (6), 1135-1148.

Gray, S.D., McDonagh, P.F., Gore, R.W., 1983. Comparison of functional and total capillary densities in fast and slow muscles of the chicken. Pflugers Arch. Eur. J. Physiol. 397 (3), 209-213.
Grounds, M.D., Garrett, K.L., Lai, M.C., Wright, W.E., Beilharz, M.W., 1992. Identification of skeletal muscle precursor cells in vivo by use of MyoD1 and myogenin probes. Cell Tissue Res. 267 (1), 99-104.

Janeczek, A., Zimna, A., Rozwadowska, N., Fraczek, M., Kucharzewska, P., Rucinski, M., et al., 2013. Genetically modified human myoblasts with eNOS may improve regenerative ability of myogenic stem cells to infarcted heart. Kardiol. Pol. 71 (10), 1048-1058.

Katagiri, T., Yamaguchi, A., Komaki, M., Abe, E., Takahashi, N., Ikeda, T., et al., 1994. Bone morphogenetic protein-2 converts the differentiation pathway of $\mathrm{C} 2 \mathrm{C} 12 \mathrm{my}-$ oblasts into the osteoblast lineage. J. Cell Biol. 127 (6 Pt 1), 1755-1766.

Keire, P., Shearer, A., Shefer, G., Yablonka-Reuveni, Z., 2013. Isolation and culture of skeletal muscle myofibers as a means to analyze satellite cells. Methods Mol. Biol. (Clifton, N.J.) 946, 431-468.

Kumar, N.M., Gilula, N.B., 1996. The gap junction communication channel. Cell 84 (3), 381-388.

Li, W., Zheng, Y., Zhang, W., Wang, Z., Xiao, J., Yuan, Y., 2015. Progression and variation of fatty infiltration of the thigh muscles in Duchenne muscular dystrophy, a muscle magnetic resonance imaging study. Neuromuscular Disord. NMD 25 (5), 375-380.

Lin, C.H., Hudson, A.J., Strickland, K.P., 1969. Fatty acid metabolism in dystrophic muscle in vitro. Life Sci. 8 (2), 21-26.

Little, T.L., Beyer, E.C., Duling, B.R., 1995. Connexin 43 and connexin 40 gap junctional proteins are present in arteriolar smooth muscle and endothelium in vivo. Am. J. Physiol. 268 (2 Pt 2), H729-39.

Mauro, A., 1961. Satellite cell of skeletal muscle fibers. J. Biophys. Biochem. Cytol. 9, 493-495.

Morash, T., Collins-Hooper, H., Mitchell, R., Patel, K., 2017. Mammalian skeletal muscle fibres promote non-muscle stem cells and non-Stem cells to adopt myogenic characteristics. Fibers 5 (1), 5

Otto, A., Collins-Hooper, H., Patel, A., Dash, P.R., Patel, K., 2011. Adult skeletal muscle stem cell migration is mediated by a blebbing/amoeboid mechanism. Rejuvenation Res. 14 (3), 249-260.

Pasut, A., Jones, A.E., Rudnicki, M.A., 2013. Isolation and culture of individual myofibers and their satellite cells from adult skeletal muscle. J. Visualized Exp. JoVE 73, e50074.

Rhee, D.Y., Zhao, X.-Q., Francis, R.J.B., Huang, G.Y., Mably, J.D., Lo, C.W., 2009. Connexin 43 regulates epicardial cell polarity and migration in coronary vascular development. Development (Cambridge, England) 136 (18), 3185-3193.

Schmalbruch, H., 1982. Skeletal muscle fibers of newborn rats are coupled by gap junctions. Dev. Biol. 91 (2), 485-490.

Schmittgen, T.D., Livak, K.J., 2008. Analyzing real-time PCR data by the comparative C(T) method. Nat. Protoc. 3 (6), 1101-1108.

Scimeca, M., Bonanno, E., Piccirilli, E., Baldi, J., Mauriello, A., Orlandi, A., et al., 2015 Satellite cells CD44 positive drive muscle regeneration in osteoarthritis patients. Stem cells Int. 2015, 469459.

Yamaguchi, A., Katagiri, T., Ikeda, T., Wozney, J.M., Rosen, V., Wang, E.A., et al., 1991. Recombinant human bone morphogenetic protein-2 stimulates osteoblastic maturation and inhibits myogenic differentiation in vitro. J. Cell Biol. 113 (3), 681-687.

Yamanouchi, K., Yada, E., Ishiguro, N., Nishihara, M., 2007. 18alpha-glycyrrhetinic acid induces phenotypic changes of skeletal muscle cells to enter adipogenesis. Cell. Physiol. Biochem. Int. J. Exp. Cell. Physiol. Biochem. Pharmacol. 20 (6), 781-790.

Yeh, H.I., Rothery, S., Dupont, E., Coppen, S.R., Severs, N.J., 1998. Individual gap junction plaques contain multiple connexins in arterial endothelium. Circ. Res. 83 (12), 1248-1263.

Yu, H., Zhang, M., Zhao, Y., Wu, P., Chen, P.-L., Li, W.-D., 2013. Insulin promotes proliferation of skeletal myoblast cells through PI3 K/Akt and MEK/ERK pathways in rats. Sheng li xue bao [Acta physiologica Sinica] 65 (1), 19-25.

Zammit, P.S., Relaix, F., Nagata, Y., Ruiz, A.P., Collins, C.A., Partridge, T.A., et al., 2006. Pax7 and myogenic progression in skeletal muscle satellite cells. J. Cell Sci. 119 (Pt 9), 1824-1832. 